\title{
Uso de extrato bruto de velame Croton heliotropiifolius como aditivo nutricional em juvenis de tilápia do Nilo
}

Use of crude Croton heliotropiifolius cane extract as nutritional additive in juveniles of Nile tilapia

\section{SOUZA, Elizângela Maria de. Doutora em Zootecnia}

IF Sertão PE - Campus Petrolina Zona Rural. Rodovia BR 235, Km 22, Projeto Senador Nilo Coelho - N4 - Petrolina - PE - Brasil. CEP: 56300-000 / Telefone: (87) 2101-8050 / E-mail: elizangela.maria@ifsertao-pe.edu.br

BARBOSA, Bárbara Soares de Siqueira. Discente do curso de bacharelado em Agronomia IF Sertão PE - Campus Petrolina Zona Rural. Rodovia BR 235, Km 22, Projeto Senador Nilo Coelho - N4 - Petrolina - PE - Brasil. CEP: 56300-000 / Telefone: (87) 2101-8050 / E-mail: barbarasoares.sbarbosa@gmail.com

LORENZO, Vitor Prates. Doutor em Produtos Naturais e Sintéticos Bioativos IF Sertão PE - Campus Petrolina Zona Rural. Rodovia BR 235, Km 22, Projeto Senador Nilo Coelho - N4 - Petrolina - PE - Brasil. CEP: 56300-000 / Telefone: (87) 2101-8050 / E-mail: vitor.lorenzo@ifsertao-pe.edu.br

AMARAL, Daniel Ferreira. Especialista em Engenharia de Segurança do Trabalho IF Sertão PE - Campus Petrolina Zona Rural. Rodovia BR 235, Km 22, Projeto Senador Nilo Coelho - N4 - Petrolina - PE - Brasil. CEP: 56300-000 / Telefone: (87) 2101-8050 / E-mail: daniel.amaral@ifsertao-pe.edu.br

VALÉRIO, Carla Samantha Rodrigues Silva. Mestra em Ciência Animal

IF Sertão PE - Campus Petrolina Zona Rural. Rodovia BR 235, Km 22, Projeto Senador Nilo Coelho - N4 - Petrolina - PE - Brasil. CEP: 56300-000 / Telefone: (87) 2101-8050 / E-mail: carla.samantha@ifsertao-pe.edu.br

SOUZA, Renilde Cordeiro de. Doutora em Zootecnia

Programa de Pós-Graduação em Zootecnia - UFBA. E-mail: renildesouza@hotmail.com

SOUZA, Anderson Miranda de. Doutor em Zootecnia

Universidade Federal do Oeste da Bahia - UFOB. E-mail: amsouza@ufbo.edu.br

FIGUEIREDO, Rozzanno Antônio Cavalcanti Reis de. Mestre em Ciência Animal

Técnico em Desenvolvimento Regional I da Companhia de Desenvolvimento dos Vales São Francisco e Parnaíba, Brasil. E-mail: zzanno@ig.com.br

\section{RESUMO}

O objetivo deste trabalho foi avaliar o efeito do extrato bruto do velame (EBV) Croton heliotropiifolius como aditivo nutricional sobre desempenho zootécnico e parâmetros bioquímicos em juvenis de tilápias do Nilo. 0 experimento foi realizado em delineamento experimental inteiramente casualizado, com cinco tratamentos, dietas com níveis crescentes do extrato $(0 ; 0,5 ; 1,0 ; 1,5$ e $2,0 \%)$ e quatro repetições. Os peixes com cerca de $12 \mathrm{~g}$ foram distribuídos em 20 caixas de $1000 \mathrm{~L}$, sistema de recirculação durante 40 dias. Ao final do período experimental foi realizada biometria e coleta de sangue, para análise de parâmetros de desempenho e bioquímicos. A inclusão do extrato de velame reduziu proporcionalmente o ganho de peso médio e as concentrações de glicose e proteínas totais do sangue. As taxas de crescimento específico e sobrevivência tiveram uma pequena melhora com a inclusão de 2,0\% do EBV na dieta. Sendo assim, conclui-se que os níveis utilizados do aditivo (EBV) no presente estudo não houve resultados significativos com relação ao desempenho de juvenis de tilápia do Nilo.

Palavras-chave: desempenho, fitoaditivo, metabolismo

\begin{abstract}
The objective of this work was to evaluate the effect of Croton heliotropiifolius (EBV) crude extract as a nutritional additive on zootechnical performance and biochemical parameters in juveniles of Nile tilapia. The experiment was conducted in a completely randomized experimental design with five treatments, diets with increasing levels of extract $(0 ; 0.5 ; 1.0 ; 1.5$ and $2.0 \%)$ and four replications. The fish with about $12 \mathrm{~g}$ were distributed in 20 boxes of 1000 $\mathrm{L}$, recirculation system for 40 days. At the end of the experimental period, biometry and blood collection were performed to analyze performance and biochemical parameters. The inclusion of cane extract reduced proportionally the average weight gain and blood glucose and total protein concentrations. The specific growth and survival rates had a small improvement with the inclusion of $2.0 \%$ of EBV in the diet. Therefore, it is concluded that the levels of the additive (EBV) used in the present study did not show significant results regarding the performance of juvenile Nile tilapia.
\end{abstract}

Key words: performance, fitoaditive, metabolism 
SOUZA, E. M.; BARBOSA, B. S. S.; LORENZO, V. P.; AMARAL, D. F.; VALÉRIO, C. S. R. S.; SOUZA, R. C. SOUZA, A. M.; FIGUEIREDO, R. A. C. R. (2018) Uso de extrato bruto de velame Croton heliotropiifolius como aditivo nutricional em juvenis de tilápia do Nilo

\section{Introdução}

Os extratos são definidos como sendo preparações de consistências líquida, sólida ou intermediária, obtidas a partir de material vegetal, são preparados por percolação, maceração ou outro método adequado e validado, utilizando etanol, água ou outro solvente que posteriormente pode ser eliminado ou não. Os extratos devem conter os princípios sápidos, aromáticos, voláteis e fixos correspondentes ao respectivo produto natural (ANVISA, 2005).

Os extratos vegetais e óleos essenciais utilizados na alimentação animal são enquadrados na categoria de aditivos fitogênicos ou fitoaditivos (SARTORI et al., 2009). 0 uso desses fitoaditivos na produção animal vêm sendo utilizados cada vez mais, devido a sua eficácia e, principalmente, ao menor número de contra-indicações e efeitos colaterais, quando comparados aos produtos sintéticos (LORENZI \& MATOS, 2008; VALLADÃO et al., 2015).

A utilização de extratos vegetais na alimentação animal tem apresentando como requisito básico a não toxicidade (SARTORI et al., 2009), pois são rapidamente metabolizados no organismo, e também são biodegradáveis, não deixando resíduos contaminantes no ambiente (SAKOMURA et al., 2014).

Na produção de peixes têm sido relatados, alguns dos benefícios da utilização de extrato de plantas na dieta desses animais, como: melhora no desempenho zootécnico, resposta imune e resistência bacteriana (ZHENG et al., 2009; VALLADÃO et al., 2015).

O uso do extrato de manjericão Ocimum basilcum na concentração de $400 \mathrm{mg} / \mathrm{Kg}$ em dieta de carpas (Cyprinus carpio) promoveu aumento no desempenho, melhor eficiência alimentar e maior taxa de sobrevivência pós-desafio com A. hydrophila (AMIRKHAN \& FIROUZBAKHSH, 2015).

Tilápias do Nilo (Oreochromis niloticus) alimentadas com 3\% de suplemento do extrato de alho na dieta, tiveram $85 \%$ de sobrevivência frente a desafio com bactérias Aeromonas hydrophila (ALY \& MOHAMED, 2010).

Trutas arco-íris (Oncorhynchus mykiss) foram alimentadas com dietas contendo extrato de alho $0 ; 0,05 ; 0,1 ; 0,5$ e $1,0 \mathrm{~g}$ por $100 \mathrm{~g}$, e desafiadas com $A$. hydrophila, ocorreu redução na taxa de mortalidade com todas as inclusões do alho (NYA et al., 2009).

A adição do extrato de urtiga-brava Urtica dioica na dieta de truta arco-íris (Oncorhynchus mykiss) desafiadas com $A$. hydrophila aumentou a taxa de sobrevivência dos grupos que receberam extrato desafiado (BILEN et al., 2016).

Dentre as espécies da Caatinga, várias são utilizadas pela população para fins fitoterápicos. A família Euphorbiaceae é uma das mais extensas entre as Fanerógamas, compreendendo cerca de 317 gêneros e 7500 espécies. O gênero Croton pertencente a essa família, é constituído de aproximadamente 1200 espécies, das quais mais de 350 estão no Brasil (BERRY et al., 2005). Estimase que na Caatinga ocorram cerca de 70 espécies de Croton (SILVA, 2010).

As espécies do gênero Croton, a exemplo do Croton heliotropiifolius, popularmente conhecida por velame comum, cassutinga, velaminho e velame de cheiro são frequentemente empregadas na medicina popular, como: antibacterianos, antifúngicos, antivirais digestivos, protetores gástricos, cicatrizantes, antiadiarréicos, relaxantes musculares, imunomodulatorios e antiinflamatórios. Suas propriedades são atribuídas aos seus metabólitos secundários, extratos e 
SOUZA, E. M.; BARBOSA, B. S. S.; LORENZO, V. P.; AMARAL, D. F.; VALÉRIO, C. S. R. S.; SOUZA, R. C. SOUZA, A. M.; FIGUEIREDO, R. A. C. R. (2018) Uso de extrato bruto de velame Croton heliotropiifolius como aditivo nutricional em juvenis de tilápia do Nilo

óleos essenciais, constituídos predominantemente por terpenóides, flavonóides e alcalóides (ABREU et al., 2011; SALATINO et al., 2007; SOUZA et al., 2010; SOUZA et al., 2012; SCALDAFERRI, 2013).

No entanto, não existem estudos a respeito do uso do extrato bruto do velame como aditivo nutricional em peixes, proposta de trabalho do presente estudo.

\section{Material e métodos}

O experimento foi conduzido nas instalações do Laboratório de Piscicultura do Instituto Federal do Sertão Pernambucano, Campus Petrolina Zona Rural, durante o período de 40 dias. A realização do experimento foi aprovada pelo Comitê de Ética no Uso de Animais (CEUA) do Instituto Federal do Sertão Pernambucano ( $\mathrm{n}^{\circ}$ 026/2016). Foram utilizadas 20 unidades experimentais (UE) distribuídas em um delineamento inteiramente casualizado (DIC), com cinco tratamentos e quatro repetições, constando cada unidade de uma caixa d'água circular de poliuretano com tampa e capacidade de $1000 \mathrm{~L}$, em um sistema de recirculação de água. Em cada UE foram acondicionados 15 juvenis de tilápia do Nilo, com peso médio inicial de $10 \mathrm{~g}$, ao todo foram necessários 300 exemplares. Antes do início do experimento com as rações testes, os animais passaram por um período de adaptação de sete dias, onde foram submetidos a tratamento profilático com cloreto de sódio $(4 \mathrm{~g} / \mathrm{L})$. Os juvenis de tilápia do Nilo foram alimentados, com cinco dietas experimentais com níveis crescentes do extrato bruto do velame $C$. heliotropiifolius $(0,0 ; 0,5 ; 1,0 ; 1,5$ e 2,0\%). 0 arraçoamento foi feito duas vezes ao dia ( $8 \mathrm{~h}$ e $16 \mathrm{~h}$ ) a um nível de $5 \%$ do peso vivo dos peixes.

A obtenção do extrato bruto do velame $C$. heliotropiifolius foi realizada no Laboratório de Química do Instituto Federal do Sertão Pernambucano Campus Petrolina Zona Rural. As folhas coletadas dos velames permaneceram em estufa de ar circulante à temperatura de $40^{\circ} \mathrm{C}$ por 72 horas para retirada de umidade. Após a secagem e completa estabilização (eliminação de água, inativação de enzimas, etc.) o material foi triturado em moinho, obtendo-se um material vegetal seco e moído das folhas. 0 material botânico foi devidamente acondicionado em um recipiente de aço inoxidável, para a realização de uma extração com o solvente n-hexano, a fim de retirar os constituintes apolares, para tanto foram realizadas três extrações num intervalo de 72 horas entre cada extração. Em seguida o material contido no recipiente foi submetido à maceração exaustiva com etanol 95\%. As soluções extrativas, hexânica e alcoólica, passaram por um processo de destilação do solvente em evaporador rotativo à pressão reduzida a uma temperatura média de 50 ${ }^{\circ} \mathrm{C}$.

As rações foram formuladas no Laboratório de Piscicultura do IF Sertão Pernambucano Campus Zona Rural, de acordo com exigência nutricional da espécie, acrescida de cada extrato bruto. Utilizou-se o programa Software SuperCrac para formulação das dietas. Os ingredientes das rações foram triturados de forma a obter a menor granulação possível. As principais fontes de proteína utilizadas foram farinha de peixe e farelo de soja; de carboidrato, fubá de milho, farinha de trigo e; de lipídios, óleo de soja. Como suplementos alimentares, foram adicionados pré-mistura vitamínico/mineral, vitamina C e antioxidante BHT (Butil-hidroxi-tolueno) (Tabela 1). Após a pesagem e a homogeneização dos ingredientes, as dietas elaboradas e acrescidas de água foram 
SOUZA, E. M.; BARBOSA, B. S. S.; LORENZO, V. P.; AMARAL, D. F.; VALÉRIO, C. S. R. S.; SOUZA, R. C. SOUZA, A. M.; FIGUEIREDO, R. A. C. R. (2018) Uso de extrato bruto de velame Croton heliotropiifolius como aditivo nutricional em juvenis de tilápia do Nilo

peletizadas em moinho de carne e desidratadas em estufa de ventilação forçada a $45^{\circ} \mathrm{C}$, durante um período de 24 horas, mantidas sob refrigeração a $5^{\circ} \mathrm{C}$ (adaptado de Furuya et al., 2013). Para o uso diário, as rações ficaram acondicionadas em recipientes de plástico com tampas herméticas, identificados por etiqueta impermeável.

Tabela 1 - Composição percentual da dieta controle utilizada para alimentação de tilápia do Nilo (Oreochromis niloticus)

\begin{tabular}{lc}
\hline Ingredientes & Composição (\%) \\
\hline Farelo de Soja & 52,0 \\
Fubá de Milho & 25,5 \\
Farinha de Trigo & 10,0 \\
Farinha de Peixe & 9,75 \\
Óleo de Soja & 0,83 \\
Sal Comum & 0,50 \\
Fosfato Bicálcio & 0,50 \\
Premix & 0,50 \\
Vitamina C & 0,20 \\
Propionato de Cálcio & 0,20 \\
BHT & 0,02 \\
\hline Total & 100
\end{tabular}

${ }^{1}$ Premix mineral e vitamínico (Supremais, Campinas-SP): Composição por quilo de produto: Vit. A = 1.200.000 UI; vit. D3 = 200.000 UI; vit. E = 12.000 mg; vit. $\mathrm{K} 3=2.400 \mathrm{mg}$; ác. Fólico (folic acid $)=120 \mathrm{mg}$; pantotenato de cálcio (calcium pantothenate) $=12.000 \mathrm{mg} ;$ vit. $\mathrm{C}=48.000 \mathrm{mg} ;$ biotina $24.000 \mathrm{mg} ; \mathrm{Fe}=10.000$ $\mathrm{mg} ; \mathrm{Cu}=600 \mathrm{mg} ; \mathrm{Mn}=4.000 \mathrm{mg} ; \mathrm{Zn}=6.000 \mathrm{mg} ; \mathrm{I}=20 \mathrm{mg}$

A limpeza das UE foi feita a cada dois dias por meio de um sifonamento das caixas d'água para a retirada das fezes e eventuais sobras de ração. As variáveis físico-químicas da água, temperatura, $\mathrm{pH}$ e oxigênio dissolvido, foram monitoradas diariamente, e a amônia semanalmente. As biometrias foram realizadas em $30 \%$ dos animais a cada 20 dias para adequação da quantidade de ração ofertada e acompanhamento do crescimento dos animais.

Ao final dos 40 dias de experimento, realizou-se biometria final (peso e comprimento). Os índices de desempenho produtivo dos diferentes tratamentos foram calculados e avaliados de acordo com os parâmetros de caráter zootécnico: ganho de peso médio (GPM) e taxa de crescimento específico (TCE). Foram amostrados aleatoriamente cinco animais de cada caixa, para coleta de cerca de 1,0 mL de sangue por punção da veia caudal, utilizando-se seringas contendo uma gota de anticoagulante (heparina), para determinação de parâmetros bioquímicos. Imediatamente após a coleta de sangue foi realizada a análise da glicose, e posteriormente o sangue foi submetido a uma centrifugação de 5.000 rpm por 5 min para a extração do plasma, para análise de proteínas totais. A análise de glicemia sanguínea foi realizada por meio de fitas reagentes de glicose em glicosímetro digital ACCU-CHEK Performa Roche Diagnosis ${ }^{\circledR}$, e para proteínas totais foi utilizado kit comercial Labtest $\circledast$.

Todos os dados são expressos em média \pm erro padrão. A homocedasticidade das variâncias foi testada pelo teste de Levene. Os dados foram avaliados de variância (ANOVA) de uma via. 0 efeito do acréscimo do extrato bruto de velame na dieta foi verificado através de análise de regressão (programa Sigma Plot 10.0, Systat Software, San Jose, CA, USA). O nível mínimo de significância de 95\% $(\mathrm{P}<0,05)$. 
SOUZA, E. M.; BARBOSA, B. S. S.; LORENZO, V. P.; AMARAL, D. F.; VALÉRIO, C. S. R. S.; SOUZA, R. C. SOUZA, A. M.; FIGUEIREDO, R. A. C. R. (2018) Uso de extrato bruto de velame Croton heliotropiifolius como aditivo nutricional em juvenis de tilápia do Nilo

\section{Resultados e Discussão}

Durante o período experimental, os parâmetros de qualidade de água do sistema mantiveram-se dentro da faixa de conforto para a tilápia do Nilo (O. niloticus), com valores médios de temperatura, oxigênio dissolvido, $\mathrm{pH}$ e amônia de: $25,7 \pm 0,8{ }^{\circ} \mathrm{C} ; 5,9 \pm 1,5 \mathrm{mg} / \mathrm{L} ; 7,0 \pm 0,6 ; 0,001$ $\pm 0,001 \mathrm{mg} / \mathrm{L}$, respectivamente.

Um dos principais objetivos da piscicultura é a melhoria do desempenho produtivo de peixes. A inclusão de extrato de velame na dieta de tilápia do Nilo não resultou em melhora no ganho de peso, pois reduziu proporcionalmente (Fig. 1A). Resultado corroborou com alguns estudos: Sahu et al. (2007) adicionaram extrato da semente de manga na dieta de carpa rohu e não houve melhora no desempenho; bem como Branco et al. (2010) estudando o efeito da utilização de extrato de alho como promotor de crescimento com juvenis de Pterophyllum scalare, também não observaram diferença significativa $(p>0,5)$ em índices como: ganho de peso e taxa de crescimento.

Efeitos inversos foram relatados por: Amirkhani \& Firouzbakhsh (2015) que ao adicionarem extrato de folhas de manjericão na dieta de carpas promoveu aumento no ganho de peso. Enquanto Nya et al. (2009), acrescentaram extrato de alho na dieta de trutas arco-íris, e obtiveram um aumento no ganho de peso. A inclusão de folhas secas e extrato da semente de manjericão ( 0 . basiculum) na dieta (ambos em $2 \%$ ) melhoraram a taxa de crescimento de tilápia híbrida ( 0 . niloticus $x$ O. aureus) e dorada, respectivamente (EL-DAKAR et al., 2008; 2015).

A inclusão de $2,0 \%$ do extrato bruto de velame C. heliotropiifolius na dieta, promoveu pequena melhora no desempenho zootécnico, no que se refere a taxa de crescimento específico (Fig. 1B) e a taxa de sobrevivência (Fig. 1C). Observando-se a taxa de sobrevivência, sugere-se duas hipóteses, sendo uma que durante os experimentos os peixes não foram acometidos por patógenos, por isso não houve registro de mortalidade dos peixes em nenhum dos tratamentos e a outra, é que os peixes podem ter tido contato com patógenos, mas a adição do extrato aumentou sua resistência imune. Estudo com desafio bacteriano mostrou o potencial de do extrato de alho em aumentar a taxa de sobrevivência dos peixes: Tilápias alimentadas com 3\% de suplemento do extrato de alho na dieta tiveram $85 \%$ de sobrevivência frente a desafio com A. hydrophila (ALY \& MOHAMED, 2010). 0 extrato de folhas de alecrim adicionado a dietas de tilápias desafiadas por Streptococcus iniae reduziu a mortalidade (ABUTBUL et al., 2004). Não há estudos prévios com a inclusão do extrato de velame (C. heliotropiifolius) na dieta de peixes.

Figura 1-Desempenho zootécnico de juvenis de tilápia do Nilo (O. niloticus) alimentados com dietas contendo diferentes concentrações de extrato bruto de velame (C. heliotropiifolius) durante 40 dias. A - Ganho de Peso Médio (GPM); B - Taxa de Crescimento Específico (TCE); C - Sobrevivência (S).
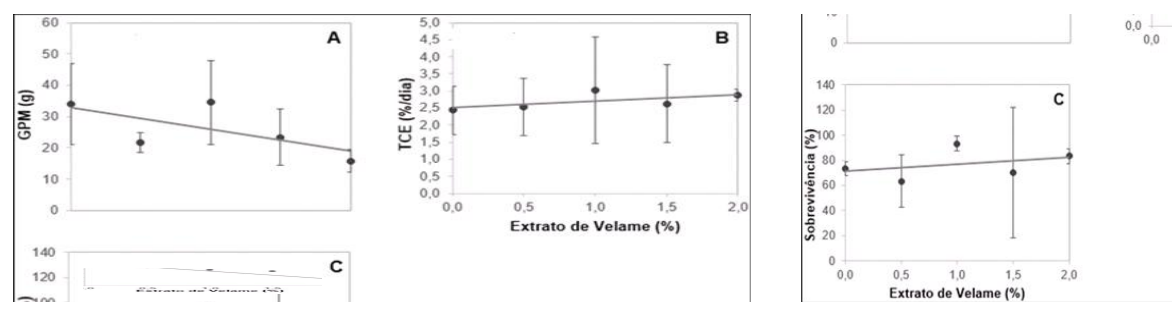

Fonte: Pesquisa direta. 
SOUZA, E. M.; BARBOSA, B. S. S.; LORENZO, V. P.; AMARAL, D. F.; VAlÉRIO, C. S. R. S.; SOUZA, R. C. SOUZA, A. M.; FIGUEIREDO, R. A. C. R. (2018) Uso de extrato bruto de velame Croton heliotropiifolius como aditivo nutricional em juvenis de tilápia do Nilo

No presente estudo houve queda nas taxas da glicose (Fig. 2B), e proteínas totais do plasma (Fig. 2B), o que demonstra que provavelmente os peixes as utilizaram como fontes energéticas para atender as necessidades fisiológicas do animal por energia, mantendo a homeostase.

De acordo com Lanna et al. (2014) a obtenção de energia presente nos alimentos é ocorre por meio da quebra (catabolismo) de três substratos: carboidratos, lipídios e proteínas. A redução da glicose neste estudo não provocou hipoglicemia nos peixes, pois os valores ficaram dentro da faixa de referência para a espécie $(14,1-92,1 \mathrm{mg} / \mathrm{dL}$ ) (TAVARES-DIAS, 2015). Os peixes quando expostos a fitoaditivos, podem apresentar homeostase ou alterações no perfil dos intermediários metabólicos (TONI et al., 2015).

A redução dos níveis plasmáticos das proteínas deste estudo, provavelmente estejam diretamente relacionadas com a redução do ganho de peso, pois as proteínas em vez de serem utilizadas para formar músculos, foram mobilizadas para suprimento energético. As proteínas corporais representam uma proporção significativa de reservas potenciais de energia, porém, sob circunstâncias normais elas não são utilizadas para a produção de energia (BAYNES \& DOMINICZAK, 2015). Alguns extratos nas dietas animais também alteram as taxas de glicose e proteínas plasmáticas: AMIRKHANI \& FIROUZBAKHSH (2015) o extrato de O. basilicum adicionado à dieta reduziu glicose e aumentou proteína total do plasma em carpa.

Figura 2 - Parâmetros bioquímicos de juvenis de tilápia do Nilo (O. niloticus) alimentados com dietas contendo diferentes concentrações de extrato bruto de velame (C. heliotropiifolius) durante 40 dias. A - Glicose; B - Proteínas totais.
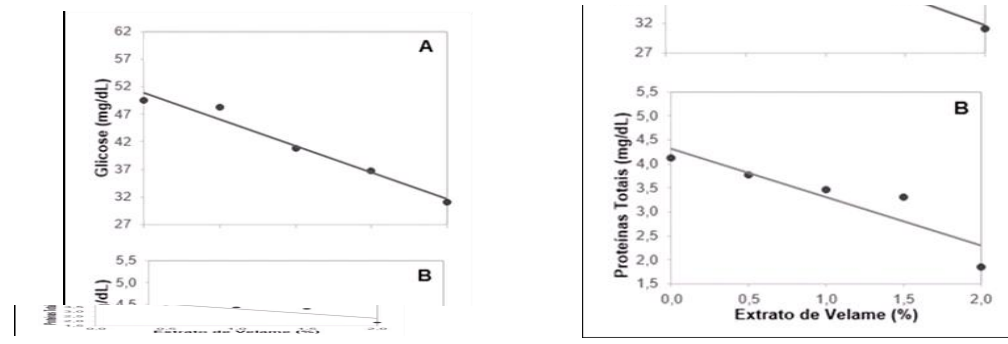

Fonte: Pesquisa direta

\section{Conclusões}

Conclui-se que os níveis utilizados do aditivo (EBV) no presente estudo não houve resultados significativos com relação ao desempenho zootécnico e parâmetros bioquímicos de juvenis de tilápia do Nilo.

\section{Agradecimentos}

À CODEVASF Petrolina-PE, pela doação dos peixes, particularmente ao Engenheiro de Pesca Rozzanno. À UNIVASF, por ceder suas instalações para realização das análises bioquímicas, em especial ao Prof. Dr. José Fernando Bibiano Melo, pela disponibilidade do Laboratório de Aquicultura. 
SOUZA, E. M.; BARBOSA, B. S. S.; LORENZO, V. P.; AMARAL, D. F.; VAlÉRIO, C. S. R. S.; SOUZA, R. C. SOUZA, A. M.; FIGUEIREDO, R. A. C. R. (2018) Uso de extrato bruto de velame Croton heliotropiifolius como aditivo nutricional em juvenis de tilápia do Nilo

\section{Referências}

ABREU A.S.; BARBOSA O.S.; MULLER, A.H., GUILHON, G.M.S.P. Constituintes químicos do caule e das cascas do caule de Croton pullei var. Glabrior (Euphorbiaceae). Revista Virtual de Iniciação Acadêmica da UFPA, v. 1:2, 2001.

ABUTBUL, S.; GOLAN-GOLDHIRSH, A.; BARAZANI, O.ZILBERG .D. Use of Rosmarinus officinalis as a treatment against Streptococcus iniae in tilapia (Oreochromis sp.), Aquaculture, v.238, p.97-105, 2004.

ALY, S. M. A: M. F. MOHAMED.. Echinacea purpurea and Allium sativum as immunostimulants in fish culture using Nile tilapia (Oreochromis niloticus). Journal of Animal Physiology and Animal Nutrition, v.94, p.31-39, 2010.

AMIRKHANI, N.; FIROUZBAKHSH, F. Protective effects of basil (Ocimum basilicum) ethanolic extract supplementation diets against experimental Aeromonas hydrophila infection in common carp (Cyprinus carpio). Aquaculture Research, v.46, p.716-724, 2015.

ANVISA - Agência Nacional de Vigilância Sanitária. Resolução da Diretoria Colegiada (RDC) n 249 de 13 de setembro de 2005. Disponível em http://www.anvisa.gov.br. Acesso em: dezembro de 2017.

BAYNES, J.W. \& DOMINICZAK, M.H. Bioquímica Médica. 4.ed. Rio de Janeiro: Elsevier, 2015, 636 p.

BERRY, P.E.; HIPP, A.L.; WURDACK, K.J.; VAN, E.E.B.; RIINA, R. Molecular phylogenetics of the giants genus Croton and tribe Crotonae (Euphorbiaceae sensu strictu) using ITS and trnL-trn-F DNA sequence data. American Journal of Botany, v.92, p.1520-1534, 2005.

BILEN, S.; UNAL, S.; GUVENSOY, H. Effects of oyster mushroom (Pleurotus ostreatus) and nettle (Urtica dioica) methanolic extracts on immune responses and resistance to Aeromonas hydrophila in rainbow trout (Oncorhynchus mykiss). Aquaculture, v.454, p.90-94, 2016.

BRANCO A.T., VIDAL JUNIOR, M.V. POLESE, M.F. UTILIZAÇÃO DE EXTRATO DE ALHO (Allium sativum) COMO PROMOTOR DE CRESCIMENTO EM PISCICULTURA. II Congresso Fluminense de Iniciação Científica e Tecnológica. 2010.

EL-DAKAR, A.Y.; HASSANIEN, G.D.; GAD, S.S.; SAKR, S.E. Use of Dried Basil Leaves as a Feeding Attractant for Hybrid Tilapia, Oreochromis niloticus $X$ Oreochromis aureus, Fingerlings. Mediterranean Aquaculture Journal, v.1, p.35- 44, 2008.

EL-DAKAR, A.Y.; SHALABY, S.M.; NEMETALLAH, B.R.; SALEH, N.E.; SAKR, E.M.; TOUTOU, M.M. Possibility of using basil (Ocimum basilicum) supplementation in Gilthead sea bream (Sparus aurata) diet. Egyptian Journal of Aquatic Research, v.41, p.203-210, 2015.

FURUYA, W.M. Nutrição de tilápias no Brasil. Revista Varia Scientia Agrárias v. 03, p. 133-150, 2013.

LANNA, E.A.T.; VIANNA, R.A.; JORGE, T.F.B. Utilização de Energia para Peixes. In: Sakomura, N.K.; Silva, J.H.V.; Costa, F.G.P.; Fernandes, J.B.K.; Hauschild, L. (Org.). Nutrição de Não Ruminantes. Jaboticabal: Funep, 2014, 678p.

LORENZI H, MATOS FJA. Plantas Medicinais do Brasil Nativas e Exóticas. 2 ed. Nova Odessa, São Paulo: Instituto Plantarum; 2008. 
SOUZA, E. M.; BARBOSA, B. S. S.; LORENZO, V. P.; AMARAL, D. F.; VALÉRIO, C. S. R. S.; SOUZA, R. C. SOUZA, A. M.; FIGUEIREDO, R. A. C. R. (2018) Uso de extrato bruto de velame Croton heliotropiifolius como aditivo nutricional em juvenis de tilápia do Nilo

NYA, E.J. \& AUSTIN, B. Use of garlic, Allium sativum, to control Aeromonas hydrophila infection in rainbow trout, Oncorhynchus mykiss (Walbaum). Journal of Fish Diseases, v.32, p. 963-970, 2009.

RIBEIRO, S.C.; CASTELO, A.S.; SILVA, B.M.P.; CUNHA, A.S.; PROIETTI JÚNIOR, A.A.; OBA-YOSHIOKA, E.T. Hematological responses of tambaqui Colossoma macropomum (Serrassalmidae) fed with diets supplemented withessential oil from Mentha piperita (Lamiaceae) and challenged with Aeromonas hydrophila. Acta Amazonica, v. 46, p.99-106, 2016.

SAHU, S.; DAS, B. K.; PRADHAN, J.; MOHAPATRA, B. C.; MISHRA, B. K.; SARANGI, N. Effect of magnifera indica kernel as a feed additive on immunity and resistance to Aeromonas hydrophila in Labeo rohita fingerlings. Fish and Shellfish Immunology, v. 23, p. 109-118, 2007.

SAKOMURA, N.K.; SILVA, J.H.V.; COSTA, F.G.P.; FERNANDES, J.B.K.; HAUSCHILD. Nutrição de Não Ruminantes. Jaboticabal: FUNEP, 678p., 2014.

SALATINO, A.; SALATINO, M.L.F.; NEGRI, G. Traditional uses, chemistry and pharmacology of Croton species (Euphorbiaceae). Journal of the Brazilian Chemical Society, v. 18 , p. 11-33, 2007.

SARTORI, J. R.; FASCINA, V. B.; CARVALHO, F. B.; GONZALES, E. Atualidades em aditivos: óleos essenciais, prebióticos e probióticos. In: IX SIMPÓSIO GOIANO DE AVICULTURA, Anais... CD-ROM, Goiânia, 2009.

SCALDAFERRI, M.M. Diversidade genética em velame pimenta (Croton linearifolius) e cassutinga (Croton heliotropiifolius) em ambientes silvestres no Sudoeste da Bahia. Dissertação apresentada ao Programa de Pós-Graduação em Ciências Ambientais da Universidade Estadual do Sudoeste da Bahia - UESB / Campus Itapetinga, 2013.

SILVA, J.S.; SALES, S.M.F.; CARNEIRO-TORRES, D.S. O gênero Croton na microregião do vale do Ipanema. Rodriguésia v.60, p.879-901, 2010.

SOUZA, D.S.; DE PAULA, V.F.; BARBOSA, L.C.A.; NASCIMENTO, J.C.; TORRES, D.S.C.; MACEDO, G.E.L. Análise sazonal dos constituintes voláteis de Croton heliotropiifolius Kunth. In: $33^{\text {a }}$ Reunião Anual da Sociedade Brasileira de Química, Águas de Lindoa-SP, 2010.

SOUZA, A.V.V.; SILVA, F.P.; SILVA, N.G.B.; SOUZA, D.D.; OLIVEIRA, F.J.V. Propagação vegetativa de velame, uma espécie medicinal nativa da Caatinga. Horticultura Brasileira, 2012.

TAVARES-DIAS, M. Parâmetros sanguíneos de referência para espécies de peixes cultivados. In: Tavares-Dias, M. e Mariano, W.S. (Org.). Aquicultura no Brasil: novas perspectivas. São Carlos, Editora Pedro e João, 2015, 345p.

TONI, C.; MARTOS-SITCHA, J. A.; RUIZ-JARABO, I.; MANCERA, J. M.; MARTÍNEZ-RODRÍGUEZ, G.; PINHEIRO, C. G.; HEINZMANN, B. M.; BALDISSEROTTO, B. Stress response in silver catfish (Rhamdia quelen) Exposed to the essential oil of Hesperozygis ringens. Fish Physiology and Biochemistry, v. 41, p. 129-138, 2015.

VALLADÃO, G.M.R.; GALLANI, S.U.; PILARSKI, F. Phytotherapy as an alternative for treating fish disease. Journal of Veterinary Pharmacology and Therapeutics, v.38, p.417-428, 2015. 
SOUZA, E. M.; BARBOSA, B. S. S.; LORENZO, V. P.; AMARAL, D. F.; VALÉRIO, C. S. R. S.; SOUZA, R. C. SOUZA, A. M.; FIGUEIREDO, R. A. C. R. (2018) Uso de extrato bruto de velame Croton heliotropiifolius como aditivo nutricional em juvenis de tilápia do Nilo

ZENG, Z.L.; TAN, J.Y.W.; LIU, H.Y.; ZHOU, X.H.; XIANG, X.; WANG, K.Y. Evaluation of oregano essential oil (Origanum heracleoticum L.) on growth, antioxidant effect and resistance against Aeromonas hydrophila in channel catfish (Ictalurus punctatus). Aquaculture, v.292, p.214-218, 2009.

ZOLFAGHARI, A.; FIROUZBAKHSH, F. The effect of Basil (Ocimum basilicum) aqueous extract on growth changes, hematology and serum biochemical parameters in rainbow trout (Oncorhynchus mykiss). Journal Veterinary Research, v.68, p.397-404, 2013. 